PROCEEDINGS OF THE

AMERICAN MATHEMATICAL SOCIETY

Volume 104, Number 3, November 1988

\title{
SEPARATELY SUBHARMONIC FUNCTIONS NEED NOT BE SUBHARMONIC
}

\author{
JAN WIEGERINCK
}

(Communicated by Irwin Kra)

\begin{abstract}
We give an example of a separately subharmonic function which is not subharmonic.
\end{abstract}

It has been known since Hartogs, cf. [3], that a function $f$ defined on a domain in $\mathbf{C}^{n}$ which is separately holomorphic, i.e. $f$ is holomorphic in each variable separately while the others remain fixed, is in fact a holomorphic function of several variables. Subsequently, by work of Lelong, see [5], and Avanissian, [2] a similar result was obtained for separately subharmonic functions which in addition are locally bounded from above. Lelong also showed that separately harmonic functions are harmonic and gave conditions for separately real-analytic functions to be real-analytic, see [6]. Siciak improved on these results, see [7].

Arsove showed in [1] that in Lelong's theorem local boundedness may be replaced by possessing an integrable majorant. The question whether separate subharmonicity in itself is enough for subharmonicity, has been around at least since 1966, cf. $[1,4]$. In this note we give an example showing that the answer is no.

The author thanks Professor S. Krantz for bringing this question to his attention.

THEOREM. There exists a nonnegative function $f$ on $\mathbf{C}^{2}$ with the following properties.

1. For every $z_{0}, w_{0} \in \mathbf{C}, f\left(z_{0}, \cdot\right)$ and $f\left(\cdot, w_{0}\right)$ are continuous subharmonic functions on $\mathbf{C}$.

2. The function $f$ is not subharmonic on $\mathbf{C}^{2}$.

$$
\begin{aligned}
& \text { ProOF. Let } a_{n}=(1 / n) e^{i /(n+1)}, n=1,2, \ldots \text { Put } \\
& \qquad \begin{aligned}
K_{n}^{\prime} & =\{z \in \mathbf{C}:|z| \leq n, 1 / n \leq \arg z \leq 2 \pi\} \cup\{0\}, \\
K_{n} & =K_{n}^{\prime} \cup\left\{a_{n}\right\}, \quad n=1,2, \ldots
\end{aligned}
\end{aligned}
$$

By Runge's theorem the holomorphic function

$$
\begin{gathered}
f_{n}(z):=0 \text { on a small neighborhood of } K_{n}^{\prime}, \\
f_{n}(z):=n+1 \text { on a small neighborhood of } a_{n},
\end{gathered}
$$

can be uniformly approximated by polynomials on $K_{n}$. Hence there exist polynomials $P_{n}$ such that $\left|P_{n}\right|<1 / 2$ on $K_{n}^{\prime}, P_{n}\left(a_{n}\right)=n+1$. Now let $h_{n}(z)=$ $\max \left\{\left|P_{n}(z)\right|-1,0\right\}$, a continuous subharmonic function on $\mathbf{C}$, which equals 0 on $K_{n}^{\prime}$.

Received by the editors October 15, 1987 and, in revised form, March 29, 1988.

1980 Mathematics Subject Classification (1985 Revision). Primary 31C05.

Research supported by a fellowship of the Royal Netherlands Academy of Arts and Sciences. 
The required function will be

$$
f(z, w)=\sum_{n}\left\{h_{n}(z) h_{n}(w)\right\}
$$

Observe that for fixed $z \in \mathbf{C}$ only finitely many of the $h_{n}(z)$ are nonzero. Therefore $f(z, \cdot)$ is a sum of finitely many continuous subharmonic functions and thus continuous and subharmonic. The same is true for $f(\cdot, w)$. However $f\left(a_{n}, a_{n}\right)$ tends to $\infty$ with $n$, so we see that $f$ is not locally bounded from above and hence not subharmonic on $\mathbf{C}^{2}$.

REMARKS. It is easy to see that our function is measurable and in fact continuous on $D:=\mathbf{C}^{2} \backslash\{(z, w): \operatorname{Im} z=\operatorname{Im} w=0, \operatorname{Re} z \geq 0, \operatorname{Re} w \geq 0\}$. Adapting our construction slightly, we can obtain that $f$ becomes smooth in each variable separately as well as on $D$. In the definition of $f$ one just uses instead of $h_{n}$ the convolution $h_{n}\left(z-a_{n} / n\right) * \phi_{n}$, where $\phi_{n}$ is a smooth, positive, radial function with sufficiently small support, while $\int \phi_{n}=1$.

In [4] the question was asked for hyperharmonic functions, a slightly more general concept than superharmonic functions. Nevertheless, $-f$ gives a negative answer in this setting, because it is not even lower semicontinuous.

\section{REFERENCES}

1. M. G. Arsove, On subharmonicity of doubly subharmonic functions, Proc. Amer. Math. Soc. 17 (1966), 622-626.

2. V. Avanissian, Fonctions plurisousharmoniques et fonctions doublement sousharmoniques. Ann. Sci. École Norm. Sup. 78 (1961), 101-161.

3. F. Hartogs, Zur Theorie der analytischen Functionen mehrerer unabhängiger Veränderlichen, insbesondere über die Darstellung derselben durch Reihen, welche nach Potenzen einer Veränderlichen fortschreiten, Math. Ann 62 (1906), 1-88.

4. M. Hervé, Analytic and plurisubharmonic functions, Lecture Notes in Math., vol. 198, SpringerVerlag, Berlin and New York, 1971.

5. P. Lelong, Les fonctions plurisousharmoniques, Ann. Sci. École Norm. Sup. 62 (1945), 301-328.

6. __ Fonctions plurisousharmoniques et fonctions analytiques de variables réelles, Ann. Inst. Fourier (Grenoble) 11 (1961), 515-562.

7. J. Siciak, Separately analytic functions and envelopes of holomorphy of some lower dimensional subsets of $\mathbf{C}^{n}$, Ann. Polon. Math. 22 (1969), 145-171.

MATHEMATISCh INStituUt DeR UVA, RoetersstraAt 15, 1018 WB AMSterdam, THE NETHERLANDS 